\title{
Challenges in management of chronic suppurative otitis media in a developing country
}

\author{
O V Akinpelu, Y B Amusa, E O Komolafe, A A Adeolu, A O Oladele, S A Ameye
}

\begin{abstract}
Background: In developing countries, the rate of complications from chronic suppurative otitis media is still high, due to factors associated with poverty. This study aimed to determine the prevalence of chronic suppurative otitis media and associated complications.

Patients and methods: We prospectively studied all patients presenting with chronic suppurative otitis media to the ear, nose and throat unit of the Obafemi Awolowo University Teaching Hospitals Complex, Ile-Ife, Nigeria, over a two-year period.

Results: One hundred and sixty new cases of chronic suppurative otitis media were seen. These constituted 11.1 per cent of all new cases and 21.5 per cent of all otological cases seen. About half (51.7 per cent) of these patients were younger than 15 years. Most patients were from rural areas and had been previously managed by unlicensed, untrained practitioners. Complications were mostly seen in children. Intracranial complications were seen in 10 (6.3 per cent) cases; this was associated with a high mortality rate.

Conclusion: This study found that, in Nigeria, a developing country, 'safe' chronic suppurative otitis media was not without serious problems. Provision of adequate health facilities may reduce such problems.
\end{abstract}

Key words: Chronic Suppurative Otitis Media; Developing Country; Late Presentation; Complications; Management

\section{Introduction}

Otitis media comprises inflammation of the middle-ear cleft. It remains a relevant topic of research both in the developing and the developed world. It is the most common otological presentation in most ENT units ${ }^{1}$ and is commonly encountered in general practice. ${ }^{2}$ The anatomical relation between the small middle-ear cleft in the temporal bone and the middle cranial fossa superiorly makes spreading infection in this space potentially fatal. ${ }^{3}$ However, the incidences of this and other forms of complications have reduced tremendously since the advent of antibiotics.

However, within rural and some semi-urban communities in developing countries such as Nigeria, the interplay of poverty and inadequate specialist ENT health care still makes complications of chronic suppurative otitis media (CSOM) a problem for the few available otolaryngologists. Late presentation and low socioeconomic factors are identifiable risk factors for the development of such complications.

This study assessed CSOM amongst patients presenting at the otorhinolaryngology unit of Obafemi Awolowo University Teaching Hospitals Complex,
Ile-Ife, Nigeria, with a view to determining its prevalence and identifying associated complications. We also discuss the problems we encountered in managing these cases.

\section{Method}

The study was prospectively carried out in a teaching hospital in south-western Nigeria.

We included 160 consecutive patients presenting at our hospital for the first time with symptoms and signs of CSOM, between January 2004 and December 2005. Data were collected using a questionnaire. This was administered to the patient or their parent by the interviewer (one of the authors) in order to obtain demographic information and a history of the disease, its predisposing factors and associated complications.

Each of the patients was fully examined and underwent otoscopy. Hearing was clinically tested using tuning forks (i.e. Rhinnes and Weber tests), and pure tone audiometry was performed for patients requiring further audiological evaluation. An X-ray 
of the mastoids and a computed tomography (CT) scan were performed as appropriate.

Data were recorded and analysed using the Statistical Package for the Social Sciences software version 11 (SPSS Inc, Chicago, Illinois, USA). Results are presented using descriptive statistics and percentages.

\section{Results}

A total of 1441 new patients were seen at our hospital between January 2004 and December 2005. Of these, 746 were otological cases, of which 160 were CSOM. Acute otitis media was seen in 51 patients, while otitis media with effusion was seen in 54 patients.

\section{Age distribution}

Forty-eight (30 per cent) of the 160 patients with CSOM were aged between zero and five years, while 21 (13.1 per cent) were aged between six and 10 years. Another 14 (8.6 per cent) were aged between 11 and 15 years. This shows that about half of the patients seen were younger children. Adolescents (16-20 years) and young adults (21-30 years) constituted 11.3 and 19.4 per cent of the patients, respectively (Table I).

\section{Sex distribution}

There were 87 males (54.4 per cent) and 73 females (45.6 per cent), giving a male to female ratio of 1:1.

\section{Place of domicile}

Sixty-seven (41.9 per cent) of the patients were from rural areas, 44 (27.5 per cent) were from semi-urban areas and 49 (30.6 per cent) were from urban areas.

\section{Laterality}

One hundred and eight of the patients had unilateral CSOM, involving the right ear in 57 (35.6 per cent) patients and the left ear in 51 (31.8 per cent). Fifty-two (32.5 per cent) patients had bilateral disease.

TABLE I

AGE DISTRIBUTION OF PATIENTS PRESENTING WITH CSOM

\begin{tabular}{lrr}
\hline Age (years) & $n$ & $\%$ \\
\hline $0-5$ & 48 & 30.0 \\
$6-10$ & 21 & 13.1 \\
$11-15$ & 14 & 8.6 \\
$16-20$ & 18 & 11.3 \\
$21-30$ & 31 & 19.4 \\
$31-40$ & 11 & 6.9 \\
$41-50$ & 8 & 5.0 \\
$51-60$ & 7 & 4.4 \\
$61-70$ & 2 & 1.3 \\
Total & 160 & 100 \\
\hline
\end{tabular}

$\mathrm{CSOM}=$ chronic suppurative otitis media
Predisposing factors

Poverty-related problems (i.e. malnutrition, overcrowding and incomplete immunisation) were found to be the most common predisposing factors in this series, being found to affect 66 (41.3 per cent) patients. Twenty-five (15.6 per cent) of the children were also found to have adenoid inflammation. Cleft palate was seen in four $(2.5$ per cent) patients. The CSOM was associated with ear trauma in 18 (11.3 per cent) patients, human immunodeficiency virus positivity in four ( 2.5 per cent), and nasopharyngeal carcinoma in one. Another child had measles with CSOM. The predisposing factor was not known in 41 patients.

\section{Duration of otorrhoea before presentation}

Patients' duration of otorrhoea prior to presentation was: two to six months in 32 (20 per cent) patients; seven to 12 months in 21 (13.1 per cent); one to five years in 59 (36.9 per cent); six to 10 years in 39 (24.4 per cent); and 10 years or more in 15 (9.4 per cent).

\section{Previous treatment before presentation}

Prior to presentation to a specialist, 54 (33.8 per cent) of the patients had received systemic antibiotics in one form or another; most of these had been procured without prescription. Sixty-one (38.1 per cent) patients had used ear drops, containing either antibiotics or other substances (including 'holy water' prescribed by some religious groups, 'goat nasal discharge' and honey). Three patients (1.9 per cent) had received some form of injection. Traditional or herbal preparations had been used by nine (5.6 per cent) patients. One patient ( 0.6 per cent) had undergone incision and drainage of mastoid abscess. Thirty-two (20.0 per cent) of the patients had received no form of prior treatment.

\section{Type of perforation}

The majority of patients (153 patients, 95.6 per cent) had a central perforation; of these, 52 had bilateral involvement. Only seven patients had marginal perforations, and these were all unilateral.

\section{Clinical presentation}

The majority of our patients $(139,86.9$ per cent) had otorrhoea with central perforations alone. Otorrhoea with perforation and granulation tissue (i.e. aural polyp) was the presentation in 16 (10 per cent) patients. Cholesteatoma with otorrhoea was seen in four (2.5 per cent) patients.

\section{Complications}

The complications observed are shown in Table II. Figures 1, 2 and 3 are some examples of these complications.

Disabling hearing loss (i.e. $40 \mathrm{~dB}$ and above) was seen in 18 patients (11.3 per cent); 11 (6.9 per cent) were aged above 15 years, while seven (4.4 per cent) were aged 15 years and below. Subperiosteal 
TABLE II

COMPLICATIONS OF CSOM SEEN IN CHILDREN AND ADULTS

\begin{tabular}{lrcr}
\hline Complications & $n$ & \multicolumn{2}{c}{ Age (years) } \\
\cline { 3 - 4 } & & $\leq 15$ & $>15$ \\
\hline Disabling hearing impairment & 18 & 7 & 11 \\
Subperiosteal mastoid abscess & 7 & 5 & 2 \\
Intracranial suppuration & 6 & 6 & 0 \\
Meningitis & 4 & 4 & 0 \\
Facial nerve palsy & 3 & 2 & 1 \\
Otitis externa & 7 & 3 & 4 \\
External auditory meatal stenosis & 1 & 1 & 0 \\
Total & 46 & 28 & 18
\end{tabular}

$\mathrm{CSOM}=$ chronic suppurative otitis media

mastoid abscess was seen in seven cases (4.4 per cent), five (3.1 per cent) of which occurred in children aged 15 years and below. Intracranial suppuration was seen in six (3.8 per cent) patients, all of them children. In all, there were 46 cases of complications, bringing the complication rate to 28.8 per cent.

\section{Treatment}

Medical treatment was instituted in 132 patients. This included frequent aural toileting, topical and systemic antibiotics, and nasal decongestants. Only four (22.2 per cent) of those with disabling hearing impairment had hearing aids fitted; others could not afford hearing aids (which were neither affordable nor readily available).

Sixteen (10 per cent) of the patients underwent surgery. Procedures included incision and drainage of subperiosteal mastoid abscess and cortical mastoidectomy in seven patients (4.4 per cent), radical mastoidectomy in two (1.3 per cent), myringoplasty in two (1.3 per cent) and aural polypectomy in five (3.1 per cent). The mortality rate in patients with intracranial suppuration was 100 per cent. Five (83.3 per cent) of these patients died before any treatment could be undertaken, while one underwent

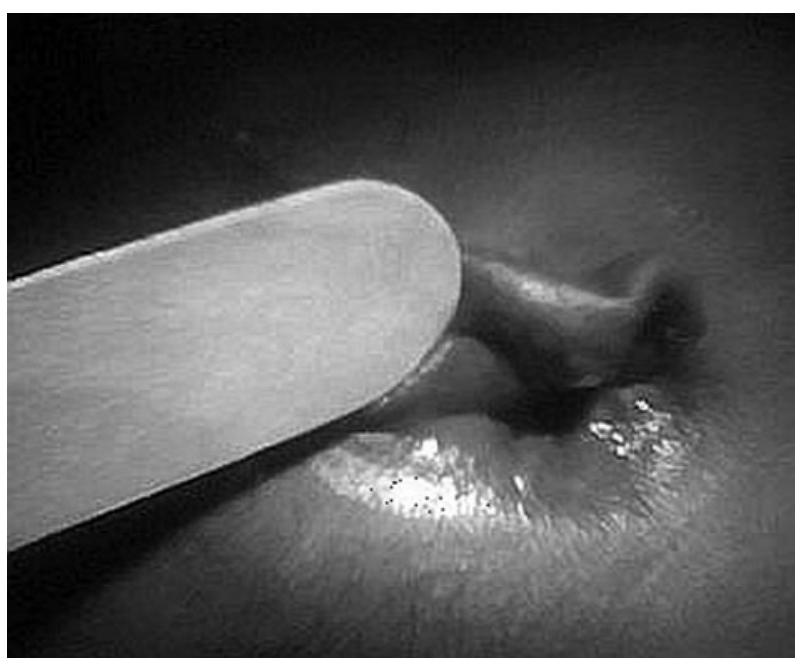

FIG. 1

Subperiosteal mastoid abscess with a discharging fistula, complicating chronic suppurative otitis media in a child.

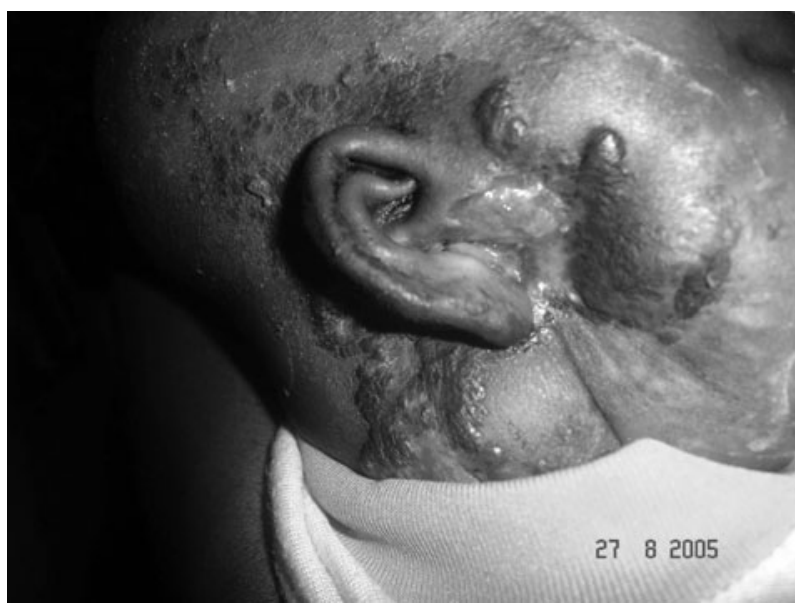

FIG. 2

A case of neglected chronic suppurative otitis media complicated by extensive otitis externa and meatal stenosis.

a burr-hole procedure for drainage of intracranial abscess and mastoidectomy but died a few hours post-operatively due to overwhelming sepsis. Adenoidectomy was performed in all patients with adenoid inflammation, in addition to medical treatment of their CSOM.

\section{Discussion}

Chronic suppurative otitis media forms the greatest clinical burden for the Nigerian otologist. It was found in 11.1 per cent of the studied population, and constituted 21.5 per cent of the otological workload. Over two decades ago, in the south-eastern part of Nigeria, Okafor found that CSOM was the most common ear disease, accounting for 44.8 per cent of patients presenting to their otolaryngology outpatient unit. ${ }^{1}$ In 2003, Lasisi et al. found CSOM to be a common problem seen by general practitioners in Ibadan, in south-western Nigeria. ${ }^{2}$ In spite of the advent of antibiotics, chronic otitis media is still a relatively common disease in children and constitutes

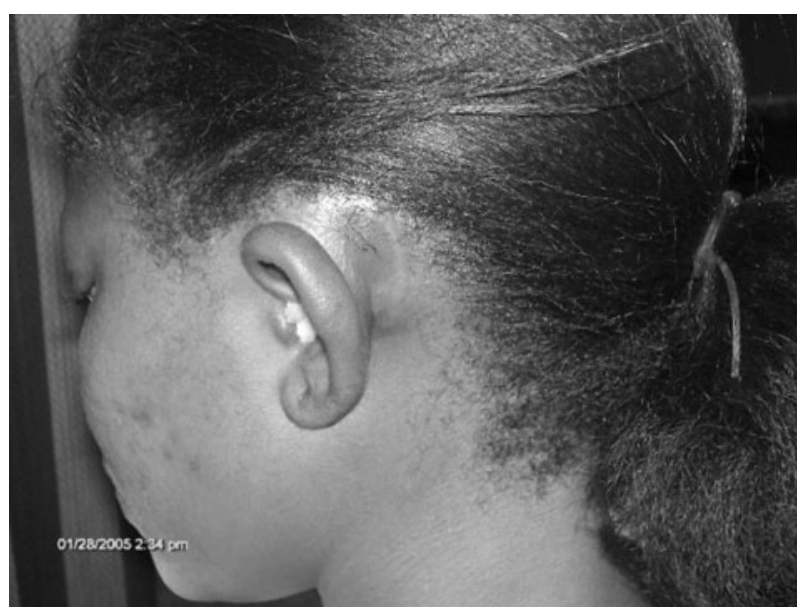

FIG. 3

Subperiosteal mastoid abscess complicating chronic suppurative otitis media in an adult. 
one of the leading causes of functional disability. ${ }^{3} \mathrm{~A}$ study performed in a rural community in the middle belt of Nigeria by Ologe et al. found a CSOM prevalence of 7.3 per cent among schoolchildren. ${ }^{4}$ In an epidemiological survey of otitis media within a semiurban community, Amusa et al. found CSOM to be prevalent in Nigerian children. ${ }^{5}$ Other studies reported that CSOM was common in rural areas in the middle belt of Nigeria, ${ }^{6}$ and among Nigerian schoolchildren.?

By comparison, CSOM occurs in an estimated 5 per cent of adults in the UK, of whom approximately 2 per cent will have active infection. ${ }^{8}$ An epidemiological study among children in Greenland showed a prevalence of 9-12 per cent. $^{9}$

The majority of those presenting to our hospital with CSOM lived in rural areas. This underlines the role of poor social economic factors in the prevalence of the disease. The majority of rural dwellers are uneducated and earn a low income, and this contributes to the delay in seeking help for a discharging ear. The rural areas of Nigeria are not adequately provided with health facilities; therefore, a patient's first medical treatment is usually in the form of 'over the counter' drugs procured from patent medicine dealers, who are usually unlicensed and untrained. The indiscriminate sale of systemic antibiotics by such dealers promotes bacterial antibiotic resistance.

Patients' lack of funds usually delays their presentation at a hospital or health facility, as money is required for transportation and for medical treatment. This situation contributes to the high rate of complications seen in our patients, including such potentially fatal conditions as subperiosteal mastoid abscess and intracranial suppuration. Such patients present with little or no money for investigations and surgery, and usually when it is almost too late for any intervention. Lasisi et al., working in Ibadan, Nigeria, found that most general practitioners preferred to treat a discharging ear with ear drops, and did not utilise any form of aural toileting or wick dressing. ${ }^{2}$

We found that the prevalence of CSOM was highest in the zero to five year age group, and approximately half our CSOM patients were aged between zero and 15 years (Table I). This corroborates the findings of Matanda et al. from the University Clinic of Kinshasa, Democratic Republic of Congo. ${ }^{10}$ We found that the prevalence of CSOM decreased with increasing age (Table I). This is similar to Okafor's 1984 findings. ${ }^{11}$

Otorrhoea was the most common symptom at presentation, followed by hearing impairment. Most of the patients we saw had waited between one and five years before seeing an otologist.

Over 90 per cent of our CSOM patients presented with a large, central perforation, i.e. a 'safe' perforation. Attic perforation (i.e. 'unsafe' perforation) was not common in our patients. We saw four cases with cholesteatoma, treated with radical mastoidectomy. Tubotympanic disease was seen in 95.6 per cent of patients; this compares well with the figures of 98.8 and 99.8 per cent found by Ologe and Nwawolo, and
Okafor, respectively. ${ }^{4,5,11}$ The low occurrence of cholesteatoma seen in our series compares well with the findings of previous studies by Okafor ${ }^{11}$ and other African authors. ${ }^{12,13}$ Similar findings have been reported in Australian Aboriginal children, with associated large central perforations and better middle-ear aeration. ${ }^{14}$

We found complications of CSOM, such as meningitis, intracranial abscess, subperiosteal mastoid abscess and mastoiditis, in 28.8 per cent of patients. Four of these complications (8.69 per cent) were associated with cholesteatoma. Even though the perforations seen were of the safe type, the complication rate was very high, close to 30 per cent. This high complication rate associated with a very high proporation tubotympanic disease compares favorably with Okafor's earlier report of CSOM from eastern Nigeria $^{11}$. It has previously been thought that more complications are found with attico-antral disease (i.e. the unsafe type of CSOM); however, it appears from our study that complications are also associated with mucosal disease. Intracranial sepsis in patients with tubotympanic disease has also been reported in studies from the developed world, ${ }^{15,16}$ although the risk of developing intracranial sepsis in adults with active CSOM is currently one in 10000 annually. ${ }^{15}$ Our patients tended to have frequent episodes of prolonged otorrhoea due to neglect and inappropriate treatment, and would often plug their ears with cotton wool balls to hide the discharge. This further worsened the problem, as the discharge was not allowed to drain freely and therefore accumulated. Poor socioeconomic factors and lack of access to adequate health facilities were confounding factors identified amongst our patients.

- In developing countries, chronic suppurative otitis media (CSOM) is usually of the 'safe' type, as cholesteatomas are less often seen. Large, central perforations allow aeration of the middle ear

- In developing countries, inadequate treatment of CSOM due to poor socioeconomic factors predisposes to complications, which can be fatal

- In communities such as these, how safe is 'safe' CSOM?

Children suffer more complications of CSOM than adults. This finding was also noted by Liang et al., working in China. ${ }^{19}$ Factors such as overcrowding, low socioeconomic status, malnutrition and poor access to immunisation may have contributed to a higher prevalence of CSOM amongst our younger patients. This is similar to the findings of Fliss et al. who reported an increased risk of CSOM in association with larger families, more siblings, a higher crowding index and care in large day care centres. $^{18}$ 
Amongst our patients suffering CSOM complications, mortality was 100 per cent in those who developed intracranial abscesses. This occurred despite exploration and neurosurgical consultation, due to late presentation and patients' inability to afford radiological investigations and antibiotics. These deaths could have been prevented.

Since the problem of late presentation was seen more among rural patients, early recognition of danger signs and prompt referral of otological cases are to be incorporated into the training of primary healthcare providers within these communities.

Disabling hearing loss (40 dB and above) was found in 11.3 per cent of our patients. This was mainly of the conductive type; sensorineural loss was seen in less than 3 per cent of the studied group.

The majority of our patients were treated medically; this was mainly due to the fact that patients could not afford surgery. Patients who were advised for myringoplasty mostly opted to use a hearing aid instead, which most of them could still not afford. Subperiosteal abscess and intracranial suppuration were the major indications for surgery in our patients. Surgery was performed in 10 per cent of our patients. This is a low rate compared with the work of Matanda et al. in Kinshasa, Democratic Republic of Congo, who performed mastoidectomy on 55 per cent of their patients. ${ }^{10}$ This was because surgery could not be afforded by most of our patients. Therefore, myringoplasty was performed in two of our patients, although many more would have benefited from it. In addition, cortical mastoidectomy was performed in five patients.

\section{Conclusion}

In Nigeria, patients with CSOM often present to tertiary health care facilities late, and often after receiving unhelpful prior treatment. The problems of late presentation and poverty compound the clinical problems and increase morbidity and mortality. Improving healthcare facilities in rural areas would reduce the incidence of CSOM complications seen in this study.

\section{References}

1 Okafor BC. Otolaryngology in south-eastern Nigeria I. Pattern of disease of the ear. Nigerian Medical Journal 1983;13:11-19

2 Lasisi OA, Fawole OO, Usman MA, Sobode MA. Case management of otitis media among GPS in South West Nigeria. Nigeria Medical Practitioner 2003;43:17-19
3 Mawson SR, Ludman H. Diseases of the Ear, a Textbook of Otology, 4th edn. London: Edward Arnold, 1979;366-425

4 Ologe FE, Nwawolo CC. Identifiable risk factors for CSOM in a rural community in Nigeria. Nigerian Quarterly Journal of Hospital Medicine 2000;10:239-42

5 Ologe FE, Nwawolo CC. Prevalence of CSOM among school children in a rural community in Nigeria. The Nigerian Postgraduate Medical Journal 2002;9:63-6

6 Ologe FE, Nwawolo CC. CSOM in school pupils in Nigeria. East African Medical Journal 2003;80:12-16

7 Amusa YB, Ijadunola IKT, Onayade OO. Epidemiology of otitis media in a local tropical African population. West African Journal of Medicine 2005;4:36-9

8 Browning GG, Gatehouse S, Calder IT. Medical management of active chronic suppurative otitis media: a controlled study. J Laryngol Otol 1988;102:491-5

9 Morris PS. Management of otitis media in a high risk population. Australian Family Physician 1988;27:1021-9

10 Matanda RN, Muyunga KC, Sabue MJ, Creten W, Van de Heyning P. Chronic suppurative otitis media and complications at the University Clinic of Kinshasa. The Royal Belgian Society for Ear, Nose and Throat, Head and Neck Surgery 2005;1:57-62

11 Okafor BC. The chronic discharging ear in Nigeria. J Laryngol Otol 1984;98:113-19

12 Ibekwe AO, Okoye BCC. Subperiosteal mastoid abscesses in CSOM. Ann Otol Rhinol Laryngol 1988;97:373-8

13 Brobby GW. Peculiarities of middle ear infections in Ghana. Ghana Medical Journal 1988;22:68-73

14 McCafferty GJ, Lewis AN, Coman WB, Mills C. A nine year study of ear disease in Australian Aboriginal children. J Laryngol Otol 1985;99:117-25

15 Nunez DA, Browning GG. Risks of developing an otogenic intracranial abscess. J Laryngol Otol 1990;104: 468-72

16 Browning GG. The unsafeness of safe ears. J Laryngol Otol 1984;98:23-6

17 Liang X, Chen S, Ou Y, Ding J, Xu Y, Yang F et al. Clinical analysis of chronic suppurative otitis media in adults and children [in Chinese]. Lin Chuang Er Bi Yan Hou Ke Za Zhi 2005; 19:594-5

18 Fliss DM, Shoban I, Leiberman A, Dagan R. Chronic suppurative otitis media without cholesteatoma in children in southern Israel: incidence and risk factors. Pediatr Infect Dis 1991;10:895-9

Address for correspondence:

Dr O V Akinpelu,

ORL Unit

Department of Surgery,

Obafemi Awolowo University,

Ile-Ife, Osun State, Nigeria.

E-mail: olubunmilola@yahoo.co.uk

Dr O V Akinpelu takes responsibility for the integrity of

the content of the paper.

Competing interests: None declared 